Article

\title{
Acoustic Issues in Open Plan Offices: A Typological Analysis
}

\author{
Sara Delle Macchie, Simone Secchi * (i) and Gianfranco Cellai \\ Department of Industrial Engineering, University of Florence, 50139 Florence, Italy; \\ sara.delle.macchie@gmail.com (S.D.M.); gianfranco.cellai@unifi.it (G.C.) \\ * Correspondence: simone.secchi@unifi.it
}

Received: 20 September 2018; Accepted: 12 November 2018; Published: 14 November 2018

check for updates

\begin{abstract}
This paper reports the acoustic issues of open plan office environments. According to a detailed research based on the scientific literature of the most suitable acoustic descriptors recommended for the open plan offices analysis, the main typological-functional configurations of these environments have been analyzed in order to identify six spatial typologies. The variation of acoustic parameters of these typologies has been evaluated by using a sound pyramid tracing software. The analysis procedure was calibrated in a case study of an office environment, where a measurement campaign was carried out. Results point out that the acoustic improvement of open plan offices can usually be achieved by introducing a sound absorbing false ceiling and dividing panels between working positions, but there are different issues depending on spatial geometries of the office. Better results are referred to office typologies characterized by reduced height and equal plan dimensions.
\end{abstract}

Keywords: open plan office; room acoustic; Indoor Environmental Quality

\section{Introduction}

Since the 1960's researchers have been addressing the acoustic problem in open-plan offices [1]. Over this period, there have been substantial changes in the nature of the sounds of office equipment; for example, the most notable change from typewriters to computers on every desk. In 1966m, Keighley [2] found that in the UK, office noise levels varied from 60 to $79 \mathrm{~dB}(\mathrm{~A})$.

In the last decades, the world of work has changed by improving the collaborative importance and mutual exchange of knowledge to be able to generate new ideas and foster innovation.

Recent experiences have highlighted the following trends:

- Significant increase of non-productive spaces, such as collaborative work spaces where workers can interact with each other in an informal way;

- Growing number of workers who use the office in a non-continuative way (teleworkers, home workers, etc.);

- Decrease in the number of individual workstations in favor of open plan spaces;

- Reduction of archive spaces by software data storage, up to their absence; and,

- Spatial flexibility to respond to different future economic and management needs.

These trends have led to the defining of the workplace as a container of activities, some of these productive, others connected to the elaboration of immaterial products, and some others became mixed areas. The answer to these needs was the diffusion of the open plan type office model, but today's workplaces need to be healthy environments that minimize the risks of illnesses to occupants to compete in the marketplace. In open plan offices, silence and concentration conditions should be 
guaranteed, because on the one hand, there is the advantage to see each other and work together, on the other, staying in a noisy environment can generate problems of concentration and general annoyance, with the consequent reduction of working productivity.

Today many people work in open plan offices where the most annoying element is irrelevant speech [3-6] that is the perception of the speech distracting for the single worker compared to activity that he is carrying out, especially based on their own semantic content.

In particular, from the results of a study that involved more than 40,000 workers in 300 U.S. office buildings [3], the authors came to the conclusion that enclosed private offices clearly outperformed open-plan layouts in most aspects of Indoor Environmental Quality, particularly in acoustics, privacy, and in proxemics issues. Benefits of enhanced 'ease of interaction' were smaller than the penalties of increased noise level and decreased privacy resulting from open-plan office configurations.

The technical literature [7-11] is consistent in affirming that open plan offices offer worse environmental conditions than traditional offices due to the lack of individual space, the lack of acoustics, and privacy requirements, in addition to the poor air and light quality and the high possibility of distraction for workers.

In open plan offices, furthermore, the control of air quality is very difficult because it is necessary to prevent the dispersion and depository of expiratory droplets that are generated locally [12]. For these reasons, the study on the type of ventilation is fundamental; some researches have investigated the impact of ventilation strategies on particle deposition in a ventilated room $[13,14]$. Other researches show that the air curtain system is efficient in removing and preventing dispersion of the expiratory droplets [15].

Therefore, the relationship between the physical and environmental qualities and satisfaction is very important because the workers spend a large amount of their time in indoor environments that affect health, productivity, and comfort.

The European Standard EN 15,251 [16] addresses this problem with a holistic view because the energy consumption of buildings depends significantly on the criteria used for the indoor environment (temperature, ventilation, and lighting) and building (including equipment) design and operation. The Annex E of the standard describes the criteria for noise and shows the correlation between thermal comfort, energy performance, and noise. When the occupants open the windows in naturally ventilated buildings to obtain adequate ventilation, the equivalent sound pressure level shall be used to evaluate noise, including the periods when the windows are open and the room is exposed to outdoor noise.

In urban areas, the environmental noise is frequently very high $[17,18]$ and so the windows are shut with the consequence of poor air quality.

In the case of Heating, Ventilation and Air Conditioning systems (HVAC), providing the required amount of air would result in unacceptable noise levels from fans and often with high-energy requirements.

As can be seen in Figure 1, experimental researches [19] show that within an office a worker can have a reduction of concentration up to $50 \%$ with very high consequences from the point of view of production. Moreover, the subjective sensitivity of the workers is important for the changing of the acoustic and environmental conditions [13].

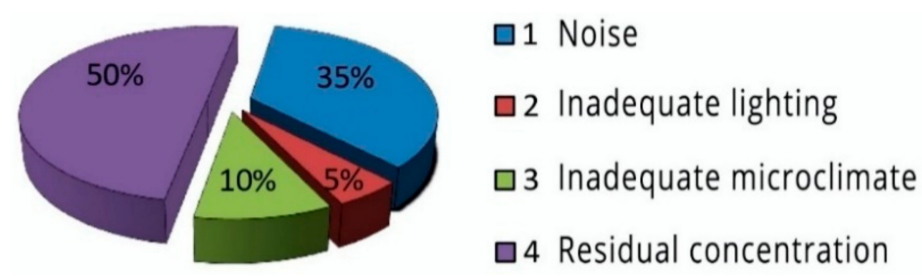

Figure 1. Influence of environmental requirements on concentration. Figure re-edited from [19].

Up to $35 \%$ of the decrease in concentration is due to the presence of noise (Figure 1). 
Moreover, people need a time variable from 15 to $20 \mathrm{~min}$ to achieve the concentration necessary to carry out intellectual activity (Figure 2).

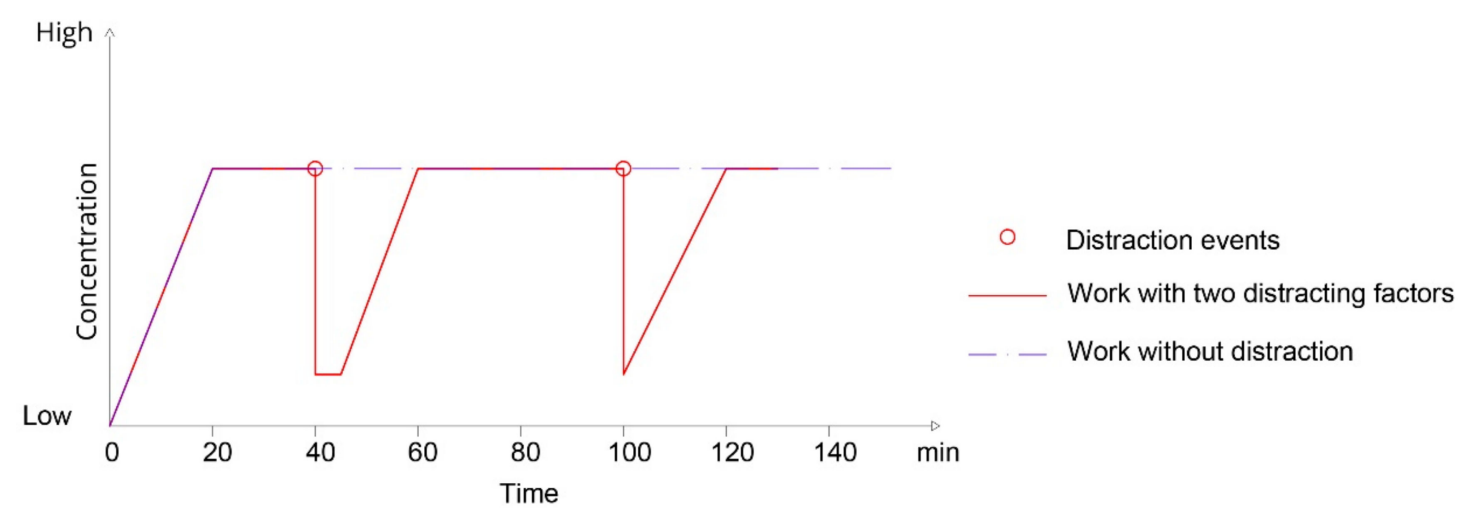

Figure 2. Time incidence of the distraction factors on worker's concentration. Figure re-edited from [19].

Phone ringing or people's speech are the most common factors of distraction in an office and determines a sudden decrease in concentration that distracts the worker in their own activity. This situation remains until the distractive phenomenon stops; after that, it can need other 15-20 min to obtain an optimal concentration level.

On the basis of these data and considering the innumerable annoyance events in an open plan office, it is clear that working quality is compromised and with it, business productivity as well.

Indoor acoustic quality of open plan offices is the object of the standards EN 15251 [16], EN ISO 3382-3 [20,21], ISO 14257 [22], and ISO/DIS 19488 [23].

According to EN ISO 3382-3, there are four acoustic quality class of open plan offices, from A, the best, to $\mathrm{D}$, the worst, on the basis of the values of three acoustic parameters that are described later.

The standard EN 15251, furthermore, gives criteria of design A-weighted Sound Pressure Level for landscaped office with a typical range from 35 to $45 \mathrm{dBA}$ and default design value of $40 \mathrm{dBA}$, similar to Class A of EN ISO 3382. It is interesting to note that the standard EN 15251 suggests that if adequate ventilation depends on the opening of the windows, in order to avoid exceeding the recommended sound levels in a work place, in the presence of noise coming from outdoors, it is necessary to reduce the noise from adjacent rooms or nearby workstations.

In Tables 1 and 2, a part of Annex A of EN ISO 3382 and Annex E of EN 15251 is reported.

Table 1. Acoustic classification of open plan offices according to EN ISO 3382-3.

\begin{tabular}{cccc}
\hline Class & DL $_{2, \mathbf{s}}$ & $\mathbf{L}_{\mathbf{p}, \mathbf{A}, \mathbf{S}, \mathbf{4 m}}$ & $\mathbf{r}_{\mathbf{D}}$ \\
\hline $\mathrm{A}$ & $\geq 11 \mathrm{~dB}$ & $\leq 46 \mathrm{~dB}$ & $\leq 5 \mathrm{~m}$ \\
$\mathrm{~B}$ & $\geq 9 \mathrm{~dB}$ & $\leq 49 \mathrm{~dB}$ & $\leq 8 \mathrm{~m}$ \\
$\mathrm{C}$ & $\geq 7 \mathrm{~dB}$ & $\leq 52 \mathrm{~dB}$ & $\leq 11 \mathrm{~m}$ \\
$\mathrm{D}$ & $<7 \mathrm{~dB}$ & $>52 \mathrm{~dB}$ & $>11 \mathrm{~m}$ \\
\hline
\end{tabular}

Table 2. Acoustic classification of open plan offices according indoor system noise criteria by EN 15251.EN 15251.

\begin{tabular}{cccc}
\hline \multirow{2}{*}{ Building } & Type of Space & \multicolumn{2}{c}{ Sound Pressure Level dBA } \\
\cline { 3 - 4 } & & Typical Range & Default Design Value \\
\hline \multirow{3}{*}{ Offices } & Small offices & 30 to 40 & 35 \\
& Conference rooms & 30 to 40 & 35 \\
& Landscaped offices & 35 to 45 & 40 \\
& Office cubicles & 35 to 45 & 40 \\
\hline
\end{tabular}


Navai and Veitch [1] conducted a comprehensive literature review on acoustical satisfaction in open plan offices and found that occupants reported decreased acoustical satisfaction when ambient levels exceeded $45 \mathrm{dBA}$.

The scientific literature [24-29] refers, for the evaluation of the acoustical quality of open plan offices, to the following parameters:

- Reverberation time, RT,

- Spatial decay, $\mathrm{D}_{2, \mathrm{~S}}$,

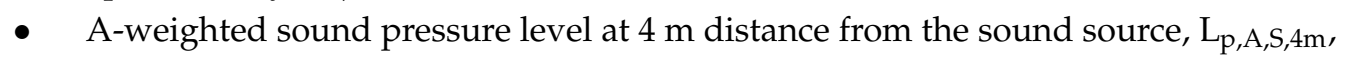

- Distraction distance, $\mathrm{r}_{\mathrm{D}}$,

- $\quad$ Speech transmission index, STI.

P. Virjonen et al. [25] have studied and analysed the acoustic quality of 16 offices and have shown that it is essential that the designer have a general view of these acoustic parameters that are the basis for a possible improvement intervention. In the following, these parameters are described and references to their limit values are given.

Acoustic performance of the interior environment is usually characterised by the Reverberation Time RT (s) that is still the most used parameter for the preliminary study of room acoustic. However, scientific literature $[25,26]$ shows that reverberation time isn't always adequate to study the acoustic properties of open plan offices.

The rate of spatial decay of sound pressure level to distance doubling $D_{2, S}$ can be preferred to reverberation time because it considers the spatial attenuation of sound. $D_{2, S}$ depends on the chosen evaluation interval; in many offices a suitable interval appears to be from 3 to $16 \mathrm{~m}$. $\mathrm{D}_{2, \mathrm{~S}}$ is given by the regression line of SPL over this region. If $\mathrm{D}_{2, \mathrm{~S}}$ will increase after acoustic treatment, this imply that the speech level will decrease faster as a function of distance.

The sound attenuation in the first $4 \mathrm{~m}$ from the source, $L_{p, A, S, 4 m}$, is a useful parameter because $4 \mathrm{~m}$ is the typical distance between two different workstations. Just like large values of $D_{2, S}$ are desirable to have a good acoustic condition in the environment, small values of $\mathrm{L}_{\mathrm{p}, \mathrm{A}, \mathrm{S}, 4 \mathrm{~m}}$ indicate that the speech is attenuated efficiently when the distance source-receiver is $4 \mathrm{~m}$.

Another important parameter for the study of the acoustic quality of open plan offices is the Speech Transmission Index (STI). Speech intelligibility means the percent of word or phrases correctly understood by one receiver compared to those pronounced by the talker and depends on the relationship between the noise level caused by the conversation and the background noise level. It varies from 0 to 1 , where 1 means $100 \%$ of intelligibility of the conversation and 0 total unintelligibility. Table 3 shows reference values of STI according to the standard IEC 60268-16:2011.

Table 3. STI reference values according to IEC 60268-16:2011.

\begin{tabular}{cccclcc}
\hline Intelligibility & Null & Negative & Inadequate & Acceptable & Good & Excellent \\
\hline STI & 0 & $<0.3$ & $0.3-0.45$ & $0.45-0.60$ & $0.60-0.75$ & $>0.75$ \\
\hline
\end{tabular}

In the short distance, the STI allows to evaluate the speech intelligibility between two colleagues who interact in the workplace and sit opposite to each other. Since the more annoying noise in an office is the private conversation of workers and the greater discomfort is caused by the lack of privacy, to transform in incomprehensible the irrelevant speech, it is needed to reduce the intelligible index at larger distances but maintaining it great in the part of office where users interact.

Appropriated values of STI index useful to guarantee an adequate privacy of the conversation between next workstations are those below 0.2 .

Kostallari et al. [30] highlighted the correlation among STI and DP (Decrease in Performance) and demonstrated that changing STI from 0.2 to 1 gives an increase of DP (\%) considerably, but when STI values are comprised from 0.7 to 1 the DP values remain constant. 
The study by R. Romano et al. [31] shows, in the case of a workstation with dimensions $3 \times 3 \mathrm{~m}$, the combinations of height of the partitions and sound-absorbing coefficient of the false ceiling that can make an acceptable confidentiality of the conversation with STI values less or equal to 0.2 : these values are possible with sound absorbing coefficient greater of 0.9 and height partition greater of $1.55 \mathrm{~m}$.

The distraction distance $r_{D}$ is defined as the distance where STI value gets off below 0.5 and is determined through linear interpolation among the point above and below STI equal to 0.5 . Small values of $r_{D}$ mean high privacy and a low speech intelligibility. In the same way, where the STI value gets off below 0.2 we can define the privacy distance $r_{P}$.

The study by Sarwono et al. [32] by computer simulation of several open-plan offices have showed the influence of workstation layout and height partition on STI, distraction distance $\mathrm{r}_{\mathrm{D}}$, and spatial decay $\mathrm{D}_{2, \mathrm{~S}}$, similar to what is done in the present study.

In open plan offices, the background noise can have a masking role and decrease the speech intelligibility contributing to increase privacy during private speeches. However, its value cannot be too high, otherwise it could cause itself a disturbing factor.

Typical values of the background noise change from 30 to $60 \mathrm{~dB}(\mathrm{~A})$ in an open plan office $[19,25,27]$; indeed, the sound pressure level can change strongly on the base of office's dimension, height, typology of the furniture and the distribution of the workstations as well as the kind of air conditioning system and the environment acoustic climate of the zone where the office is located.

Working in a noisy environment can produce concentration problems and annoyance, but in the most serious cases, stress and symptoms of fatigue as well. The renovation of these environments can be faced by little recurring modifications such as the correct choice of furniture components and false ceiling, the optimization of aggregation criteria, and orientation of workstations.

In general terms, the control of the acoustic comfort in working environment concerns the following factors that determine the acoustic climate of the space: The sound source typologies, the workstation distribution on the space, the presence of high partitions or screen between the workstations, the constructive typology of the building (especially about sound-isolation and sound-absorbing requests), the characterization of the background noise determined by continuous (noise of computer operation, HVAC systems, mounting background noise, etc.), and discontinuous sound sources (mobile phone ring, play of copier, etc.), and finally the windows opening time in areas with high external noise if adequate ventilation depends on the opening of the windows.

Furthermore, disproportionate spaces such as open plan offices, with height lesser than the other plan dimensions, are characterized by an un-diffused sound field. In fact, in these environments, the spatial decays are very different from each other in the various directions.

One first solution to the problem consists in inserting systems that increase the sound-absorption reducing the effect of reflections and so the overall sound level. It is generally recommendable to act first on the false ceiling and on the taller part of the walls, then with fixed or mobile systems to divide the space or with vertical (baffles) or horizontal elements suspended to the ceiling. In very large and high open space offices, a widely used technique is to create acoustic islands by portions of ceilings suspended on workstations.

To reduce perceived distraction, another solution consists in increasing the number of quiet rooms: Haapakangas et al. [33] have shown that an open-plan office with more quiet rooms yields better results in terms of perceived distractions, environmental satisfaction, collaboration, and stress symptoms than an office with less quiet rooms.

The selection of the materials and systems to insert in a space to improve acoustic quality must consider the frequency sound absorbing coefficient $\alpha$ of the materials. An optimal solution consists in vibration panels or resonators, which also works very well at low frequencies, with porous materials in the cavity that, instead, works better to in a medium-high frequency. Many kinds of materials can be suitable for this purpose, also considering the case of sustainable materials [34].

Regarding performances of the partition panels, in addition to the sound-absorbing coefficient, they must also guarantee the sound-insulation respect to direct transmission. 
V. Hongisto et al. [24] carried out a study on an open space office with 135 employees that has been the object of refurbishment to improve thermal and ergonomic conditions, privacy (hearing and visual), and spatial density. The purpose of the research group was to demonstrate, with measurements before and after the renovation, the presence of a close relationship between environment quality and satisfaction for the workers. The renovation of the working environment has been made to reduce the occupation density, increase the sound-absorbing surfaces already present, and change the partitions with other higher. These environmental changes improved the satisfaction and working productivity.

The introduction, in an open plan office of high partitions, is usually the better intervention, especially if the office has a sound-absorbing false-ceiling.

On the basis of scientific literature studies $[11,19,24,28]$, the minimum values to guarantee a good performance of the division panels are the following:

- $\quad$ Heigh: $\mathrm{h} \geq 1.80 \mathrm{~m}$;

- Lenght: $1 \geq 1.20 \mathrm{~m}$;

- Thickness: $\mathrm{s} \leq 0.30 \mathrm{~m}$;

- Sound-absorbing coefficient: $\alpha_{\mathrm{w}} \geq 0.8$.

Another technique used to reduce the general annoyance in open plan offices and decrease privacy problem is sound masking, which is widespread, especially in the USA since the 1960's and today also diffuse in North Europe [35]. Anyway, sound masking can have disturbing characteristics for the employees, so the research of optimal spectra is open again.

The acoustic effect of the above described techniques can be very different when dimensions and proportion of the open space office are varied. For example, the effect of a dividing panel can be irrelevant when the office is very reverberant or very high.

In the literature, there is a lack of systematic approaches to the effect of office dimensions and proportions on the variation of the main acoustic parameters described above. For this reason, the aim of this paper is to analyze this effect with reference to different kinds of open plan offices, which are representative of the most widespread kinds of offices.

\section{Methods and Instruments}

In this study, a room acoustic analysis of six spatial typologies of open plan offices has been carried out by means of a ray tracing software, also considering the effect of different kinds of acoustic treatment. The results have been analyzed with reference to the acoustic parameters described in the previous section.

In open plan offices, acoustics are influenced, largely, by the environment dimensions, both in plan and in elevation, so the following six typical spatial typologies, representative of the most spread kinds of open plan offices, have been analyzed:

A. office with squared plan $\left(256 \mathrm{~m}^{2}\right)$ and height of $3 \mathrm{~m}$;

B. office with squared plan $\left(256 \mathrm{~m}^{2}\right)$ and height of $6 \mathrm{~m}$;

C. office with lengthened plan $\left(720 \mathrm{~m}^{2}\right)$ and height of $4 \mathrm{~m}$;

D. office with lengthened plan $\left(720 \mathrm{~m}^{2}\right)$ and height of $6 \mathrm{~m}$;

E. office with irregular plan $\left(216 \mathrm{~m}^{2}\right)$ and height of $3 \mathrm{~m}$; and

F. office with irregular plan $\left(216 \mathrm{~m}^{2}\right)$ and height of $6 \mathrm{~m}$.

The offices type $C$ and D represent many cases where old industrial buildings have been renovated and converted into tertiary work-spaces. The typologies with the irregular plan represent, still in a schematic way, a morphology with less rigid spaces within the most modern buildings of contemporary architecture.

Each of the six types, described above, have been studied in the four different configurations described in Table 4. The sound absorption coefficients used for each material are shown in Table 5. 
Table 4. The configurations analyzed for each of the six office typologies.

\begin{tabular}{cccccccccc}
\hline & Floor & Plaster & Windows & Tables & Chairs & Doors & False Ceiling & High Partition & Screen \\
\hline 1 & $\mathrm{x}$ & $\mathrm{x}$ & $\mathrm{x}$ & $\mathrm{x}$ & $\mathrm{x}$ & $\mathrm{x}$ & & & \\
2 & $\mathrm{x}$ & $\mathrm{x}$ & $\mathrm{x}$ & $\mathrm{x}$ & $\mathrm{x}$ & $\mathrm{x}$ & $\mathrm{x}$ & & \\
3 & $\mathrm{x}$ & $\mathrm{x}$ & $\mathrm{x}$ & $\mathrm{x}$ & $\mathrm{x}$ & $\mathrm{x}$ & $\mathrm{x}$ & $\mathrm{x}$ & $\mathrm{x}$ \\
4 & $\mathrm{x}$ & $\mathrm{x}$ & $\mathrm{x}$ & $\mathrm{x}$ & $\mathrm{x}$ & $\mathrm{x}$ & $\mathrm{x}$ & $\mathrm{x}$ & $\mathrm{x}$ \\
\hline
\end{tabular}

Table 5. Sound absorption coefficient of the materials used for the simulations.

\begin{tabular}{ccccccc}
\hline & \multicolumn{7}{c}{ Sound Absorbing Coefficient $\alpha$} \\
\hline Materials & $\mathbf{1 2 5} \mathbf{~ H z}$ & $\mathbf{2 5 0 ~ H z}$ & $\mathbf{5 0 0 ~ H z}$ & $\mathbf{1 0 0 0} \mathbf{~ H z}$ & $\mathbf{2 0 0 0 ~} \mathbf{~ z z}$ & $\mathbf{4 0 0 0} \mathbf{~ H z}$ \\
\hline Floor & 0.022 & 0.032 & 0.032 & 0.032 & 0.043 & 0.054 \\
Plaster & 0.065 & 0.065 & 0.065 & 0.076 & 0.098 & 0.154 \\
Window & 0.395 & 0.279 & 0.199 & 0.131 & 0.076 & 0.043 \\
Tables & 0.120 & 0.120 & 0.131 & 0.131 & 0.109 & 0.109 \\
Chairs & 0.221 & 0.279 & 0.325 & 0.348 & 0.325 & 0.279 \\
Door & 0.120 & 0.131 & 0.131 & 0.131 & 0.109 & 0.109 \\
Sound-absorbing false ceiling & 0.240 & 0.70 & 0.970 & 0.900 & 0.950 & 0.850 \\
High partition & 0.763 & 0.866 & 0.892 & 0.958 & 0.958 & 1.00 \\
Screen & 0.510 & 0.700 & 0.800 & 0.770 & 0.600 & 0.500 \\
\hline
\end{tabular}

The acoustic simulations have been carried out by means of the pyramid tracing predictive software Ramsete ${ }^{\circledR}$ in the presence of furniture, but in the absence of people. This Pyramid Tracing algorithm is capable of solving the sound propagation problems following the geometrical acoustics assumptions. It takes into account specular reflections over sound absorbing surfaces, the diffraction effect over free edges of screens, and sound insulation of partitions, holes, windows, and doors. The diffraction effect is computed with the Keller/Maekawa formula [36]. This method produces an important approximation of the wave propagation over an obstacle. Anyway, the software outputs have been widely validated in literature with reference to large rooms [36], as well as to common indoor environments [37].

In this study, the software outputs have been analyzed with reference to a case study of an office (Figure 3) where measurements of some of the previously descripted acoustical parameters were carried out [38]. The office analyzed in this part of the study is a typical office characterized by hard surfaces and typical furniture, with 11 workstations and the following main dimensions: $8.1 \mathrm{~m}$ (width) $\times 17.35 \mathrm{~m}$ (length) $\times 3 \mathrm{~m}$ (height).

For the measurements the following instrumentation was used (Figure 3):

- $\quad 01 \mathrm{~dB}$ sound source dodecahedron;

- $01 \mathrm{~dB}$ sound amplifier;

- double channel sound analyzer $01 \mathrm{~dB}$ Symphonie, with real time analysis in $1 / 3$ octave frequency bands; and

- two diffuse field $1 / 2$ Grass microphones with preamplifiers.

Measurements of the Reverberation Time were carried out over 12 points randomly distributed over the entire volume of the office.

Figures 4 and 5 show the comparison between calculated and measured values of the Reverberation Time (as space averaged values) and of the spatial decay over the longitudinal dimension of the office.

Figure 4 also shows the error bars of the Reverberation Time measurements, which indicate plus and minus the value of the standard deviation of the measurement over the 12 points. It can be noted that the uncertainty of the results is greater at lower frequencies, as already shown in the previous studies of the author [38]. This is due to the lack of uniformity of the sound field at low frequency. 
At mid frequency $(500 \mathrm{~Hz})$, the standard deviation is $0.07 \mathrm{~s}$, which is about $10 \%$ of the average value of the reverberation time.

The comparisons between measured and simulated values shown in Figures 4 and 5 point out a good agreement with reference to the examined parameters.

Simulations were carried out by analyzing the following configurations for each of the six spatial typologies (Table 4 and Figure 6):

1. no surfaces with sound-absorbing materials;

2. insertion of the false ceiling in gypsum plaster with $\alpha_{\mathrm{W}}=0.7$;

3. equal to (2) but with addition of $2 \mathrm{~m}$ high sound-absorbing partitions between workstations characterized by $\alpha_{\mathrm{w}}=0.85$ and $\mathrm{R}_{\mathrm{w}}=34 \mathrm{~dB}$; and

4. equal to (3) but with addition of low divisors on the table surface, placed between two opposite working people with $\alpha_{\mathrm{w}}=0.8$.

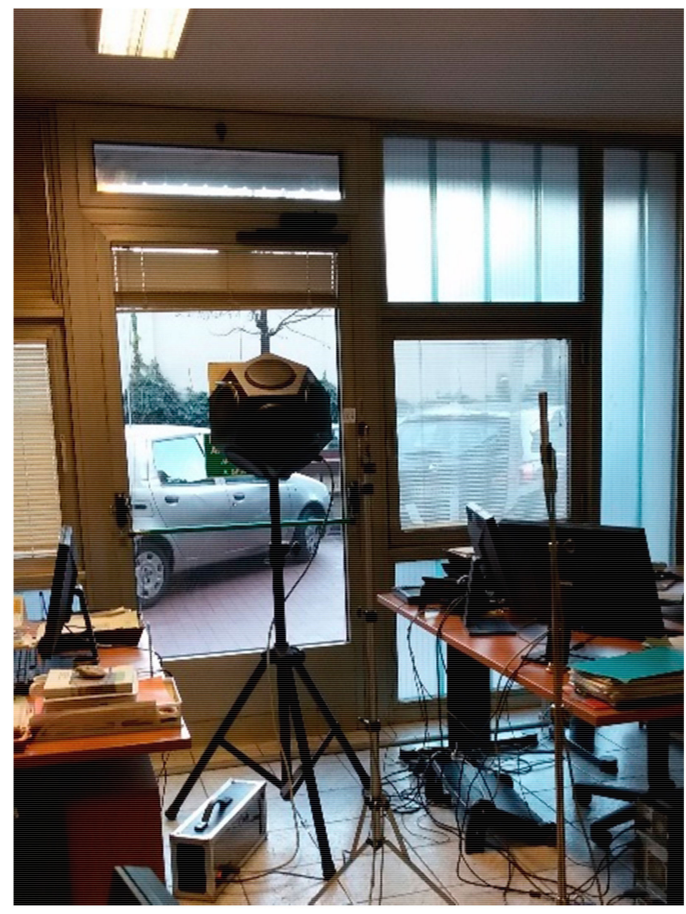

Figure 3. Measurement instrumentation in the case study office.

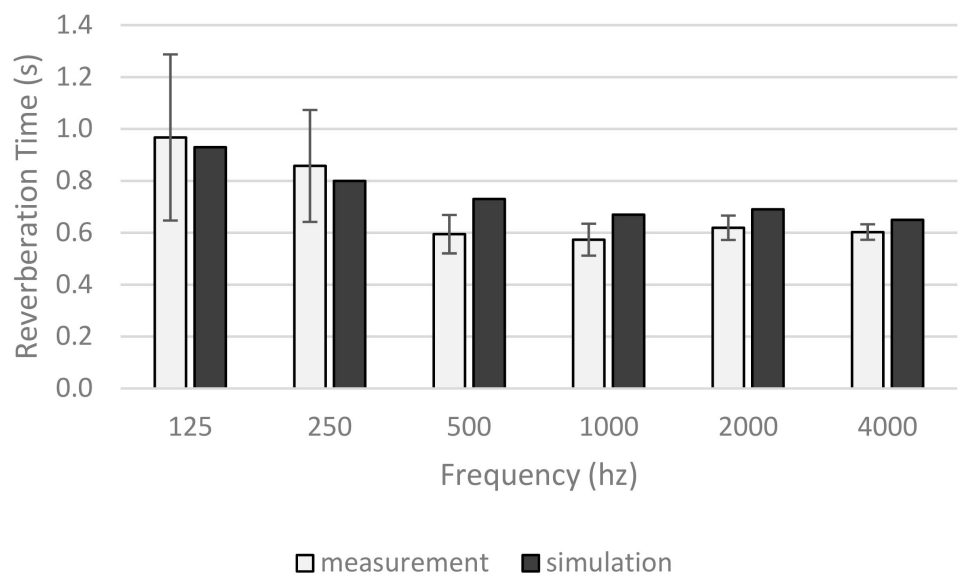

Figure 4. Comparison between simulated and measured values of the Reverberation Time (RT) in the case study. The error bars indicate plus and minus the standard deviation of the measurements. 


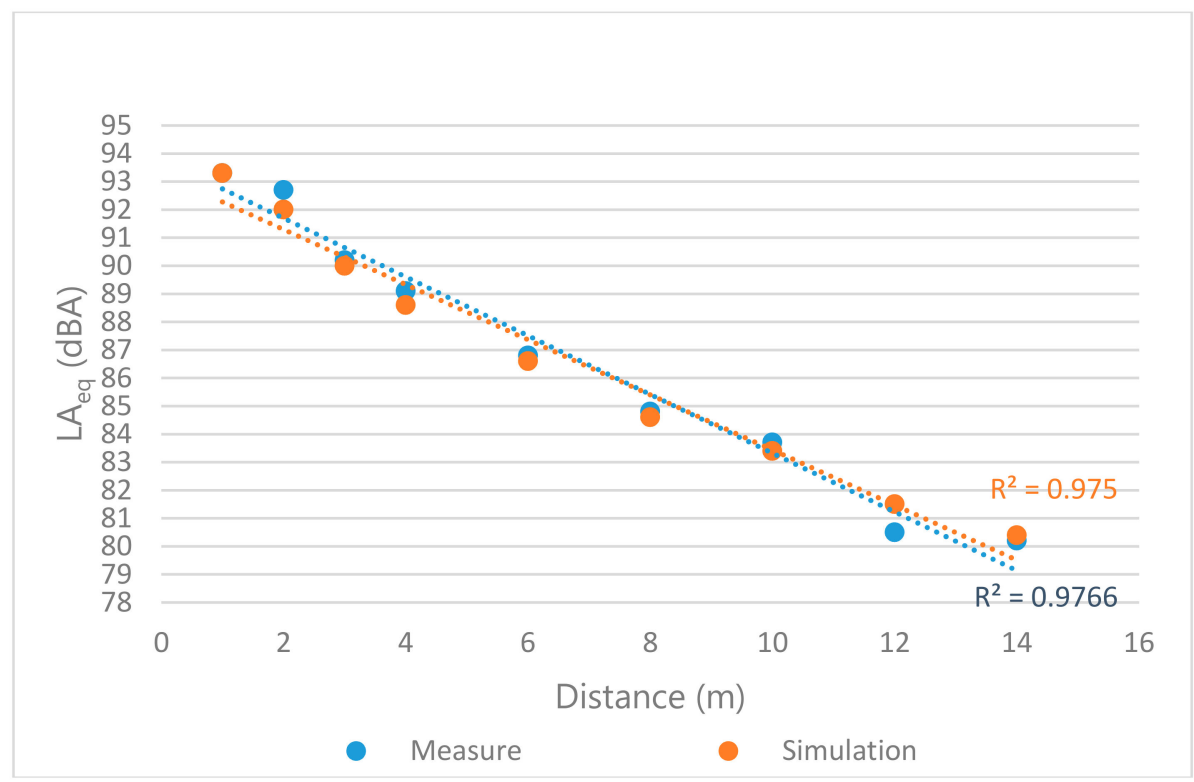

Figure 5. Comparison between simulated and measured values of the Sound Pressure Level (SPL) over the longitudinal dimension of the case study.
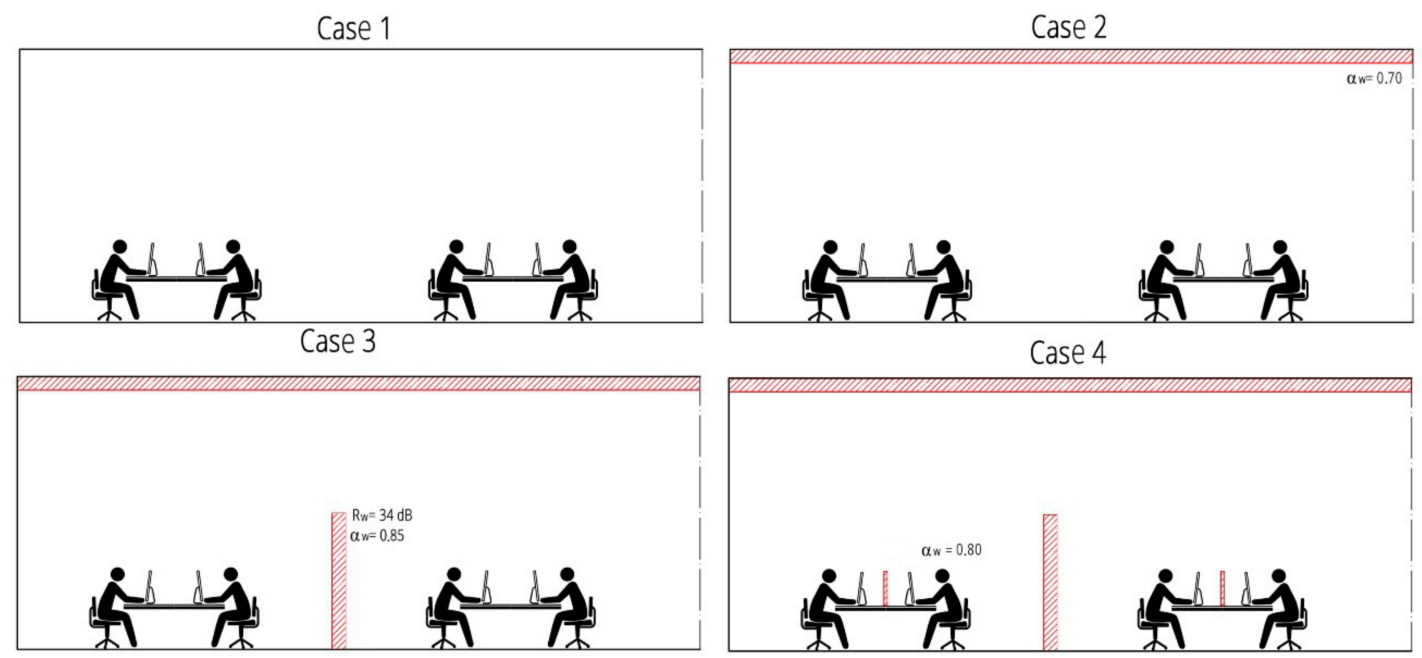

Figure 6. The examined office configurations.

Globally, 24 series of simulations were carried out (6 spatial configurations for 4 internal material typologies).

The sound source used for the acoustic simulations had the human voice spectrum and directivity, according to the standard ISO 9921 [39]. The receivers have been positioned, such as the sound source, at $1.20 \mathrm{~m}$ from the ground, located on a straight line and distance of $1 \mathrm{~m}$ from themselves.

The following parameters, previously described, were calculated:

- the spatial decay $\mathrm{D}_{2,5}$, to the short distance, in order to evaluate the performance within the same working area, and to a greater distance, from 4 to $8 \mathrm{~m}$;

- the A-weighted Sound Pressure Level $\mathrm{L}_{\mathrm{p}, \mathrm{A}, \mathrm{S}, 2 \mathrm{~m}}$ at $2 \mathrm{~m}$ and $\mathrm{L}_{\mathrm{p}, \mathrm{A}, \mathrm{S}, 4 \mathrm{~m}}$ at $4 \mathrm{~m}$ distance from the sound source;

- $\quad$ the Reverberation Time RT; and

- the Speech Transmission Index (STI) and the distraction distance $\mathrm{r}_{\mathrm{D}}$. 
We obtained the distraction distance $r_{D}$ by the Speech Transmission Index (STI), taking a medium background noise as input, referring to the values highlighted by researchers [40] and on the basis of the background noise level measured in a typical working morning in the case study office (Figure 7) [40].

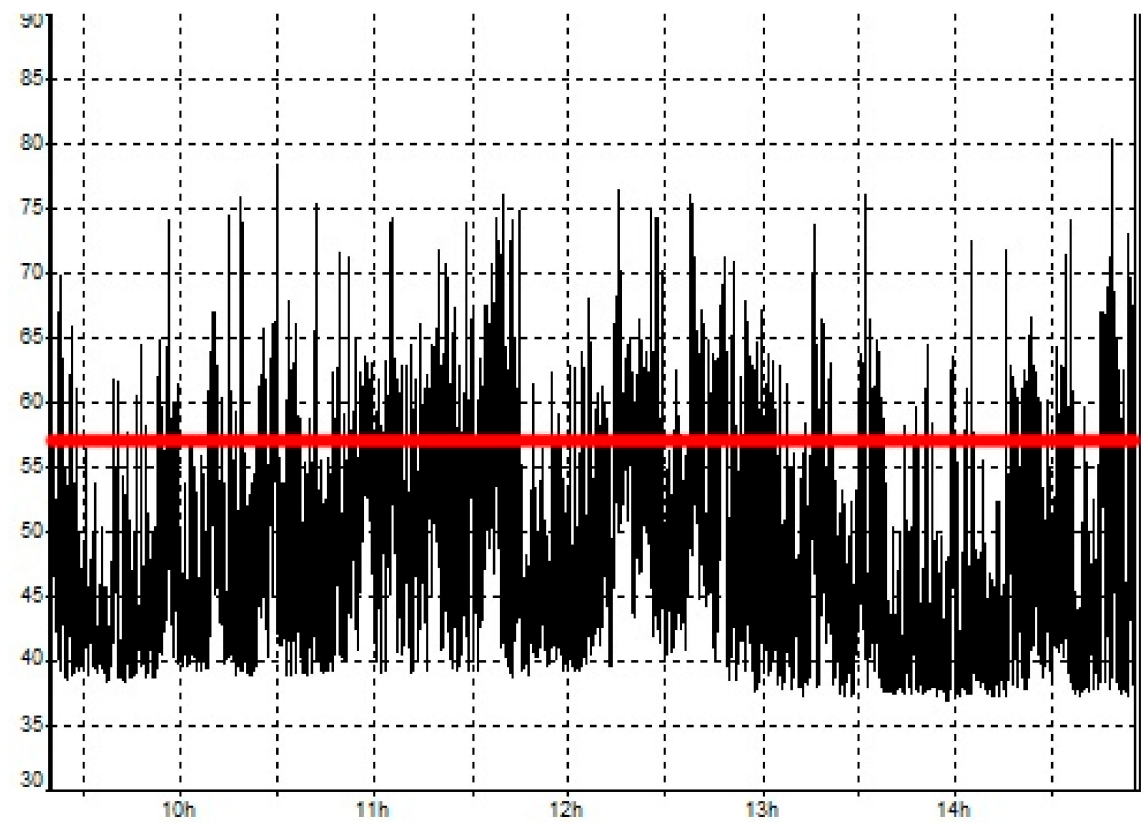

Figure 7. Environmental noise measured in the case study office (Figure 3) in the time slot 9:30-15:00 $\left(\mathrm{L}_{\mathrm{Aeq}}=57 \mathrm{~dB}(\mathrm{~A})\right)[40]$.

The second step of this study involved the insertion of a large number of receivers (every $20 \mathrm{~cm}$ ) within a small part of the virtual model analyzed, in order to better describe the sound propagation in the various configurations.

\section{Results and Discussion}

Simulation results show a similar behavior of the six office types when varying the acoustical properties of the materials introduced.

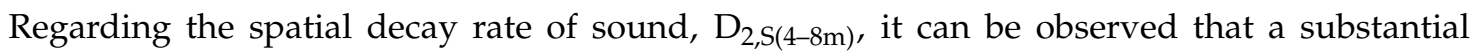
improvement from configuration 1 to 3 , thus, thanks to the insertion of both the sound-absorbing false ceiling and the partitions panels (Table 4), as already shown by previous studies [41]. The configuration 4 doesn't produce any additional improvement.

Typology $\mathrm{A}$ is the open plan situation that is most affected by the changes in the environment acoustic properties where $\mathrm{D}_{2, \mathrm{~S}}$ reaches the value of $5 \mathrm{~dB}$ in configuration 3 . However, every configuration falls within class $\mathrm{D}$ according to the classification given in Table 1 from the standard ISO 3382-3, since they always have $\mathrm{D}_{2, \mathrm{~S}}<7 \mathrm{~dB}$; this suggests the necessity of adding absorbing material also on the lateral walls. Anyway, it must be underlined that this parameter has been obtained from the trend line on $\mathrm{L}_{\text {Aeq }}$ vs. distance, that, in cases 3 and 4, have a correlation coefficient lower than in cases 1 and 2 . For example, in office type $A$, the correlation coefficient $R^{2}$ is equal to 0.91 in case 1 , while in case 3 , this value is 0.83 (Figure 8 ).

This phenomenon is caused by the diffraction effect of the sound that determines a decrease of the sound level immediately after the high partition and the screens in the workstations, while in the successive points, this effect is reduced and the sound pressure level increases again, according to the room's acoustic quality. The diffraction effect determines great data dispersion, and consequently, a lower correlation coefficient.

This latter problem is particularly strong in case 3, where the sound spatial decay in the box (the portion of the office between two opposite separating screens), called $\mathrm{D}_{2, \mathrm{~S}(\mathrm{box})}$, shows negative 
values for all kinds of offices except office A (Table 6). This is due to the fact that the sound decay within the box has been obtained by arithmetical subtraction and not according to the trend line. As shown in Figures 9 and 10, referred to as an example of office type C, the receivers used to extract $D_{2, S(b o x)}$ are $R_{x}$ and $R_{x+2}$. The receiver $R_{x}$ is situated behind the high partition and is little affected by the diffraction effect, and as a consequence, the Sound Pressure Level (SPL) is lower than in $R_{x+2}$, even if this last is further from the source. For example, in office type $C$, in case $3, L_{\text {Aeq }}$ in receiver $R_{x}$ is equal to $43.3 \mathrm{~dB}(\mathrm{~A})$ while in $\mathrm{R}_{\mathrm{x}+2}$ is equal to $44.6 \mathrm{~dB}(\mathrm{~A})$, so the $\mathrm{D}_{2, \mathrm{~s}(\text { box })}$ obtained from arithmetical subtraction is a negative value.

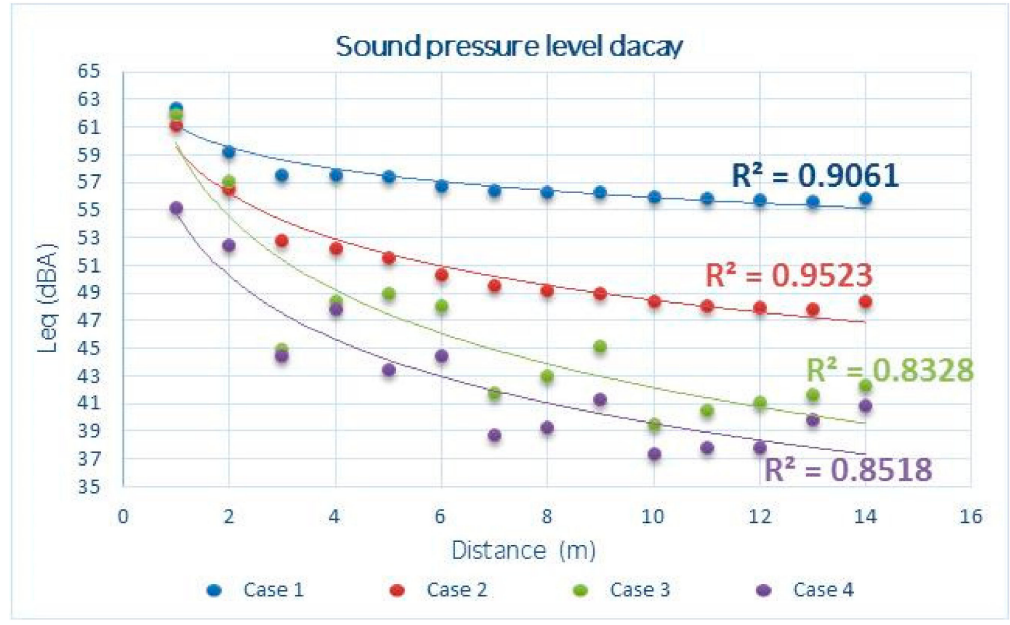

Figure 8. Sound pressure level vs. distance from the source and $\mathrm{R}^{2}$ values of logarithmic trend lines for office A.

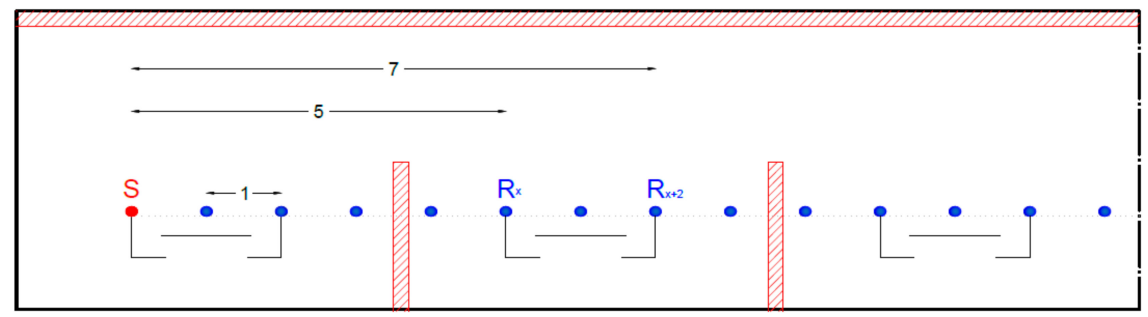

Figure 9. Example of sound source and receivers used to obtain $\mathrm{D}_{2, \mathrm{~S}(\mathrm{box})}$ in ' $\mathrm{C}$ ' office type.
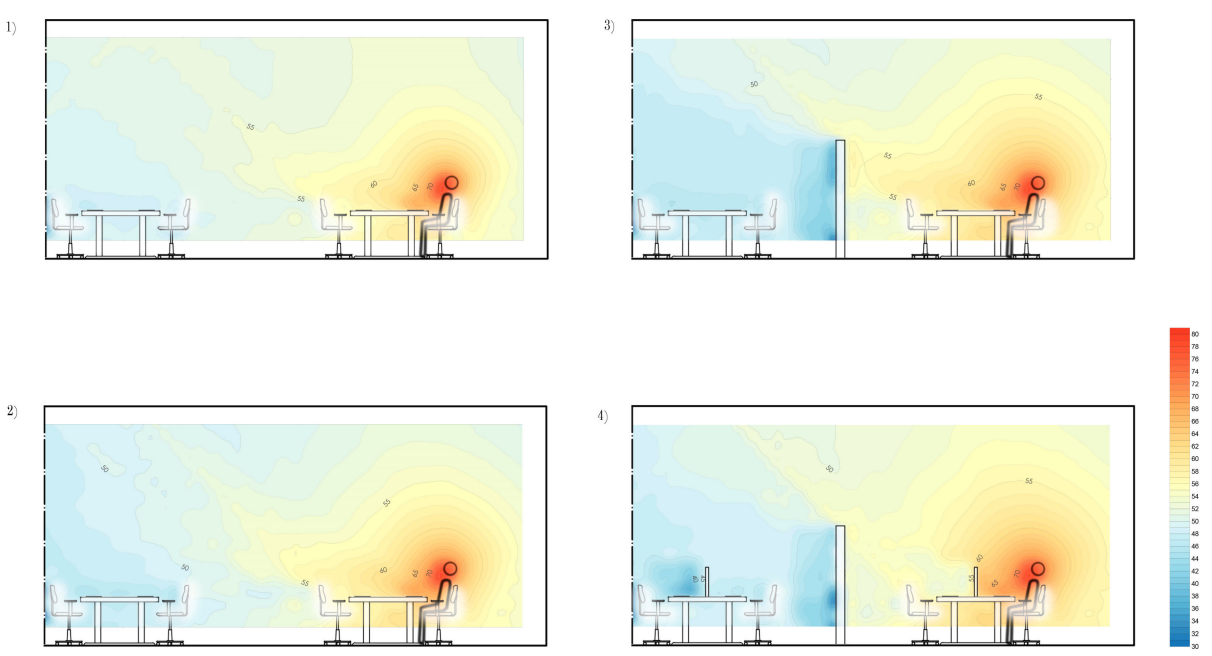

Figure 10. Sound propagation map in the four conditions studied in office type C. 
However, by considering the sound pressure level absolute value, we can still deduce a positive result from the introduction of the panel and the low screens on the tables. With reference to office type $\mathrm{A}$, there is a reduction of approximately $7 \mathrm{~dB}$ from the configurations 1 to the configuration 4 , while at $4 \mathrm{~m}$, the distance from the sound source of the reduction is almost $10 \mathrm{~dB}$.

In the office type B, there is the same difference of the sound level at a short distance, while the introduction of the partition panels and low screens have a greater effect causing a reduction of SPL of $13.3 \mathrm{~dB}$ at $4 \mathrm{~m}$ from the source.

Figure 10 shows the map of A weighted Sound Pressure Levels in office type $C$ with receivers set every $20 \mathrm{~cm}$. This is a detailed map of the propagation of sound over the various obstacles (desk screen and dividing panels). It can be noted that the diffraction effect simulated by the pyramid tracing software over the small screens on the desks (bottom, right of the Figure) and over the dividing panels (top, right of the Figure). As a consequence of this diffraction effect, the small screens over the desks are almost ineffective to reduce the sound propagation from the speaker to the opposite worker.

Another important evaluation concerns the classification reported in Table 1 in accordance with the

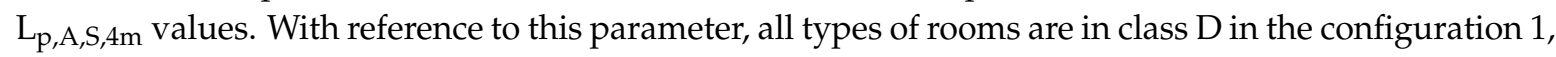
while in configurations 3 and 4 , they reach class A or B. Therefore, the changes made to the environment are significantly positive for the acoustic quality of the room, in terms of SPL reduction at greater distances. This agrees with the conclusions of previous studies $[8,24]$.

With reference to Reverberation Time, with the introduction of a sound-absorbing false ceiling, a clear change occurs in all the spatial morphologies. This reduction is more evident in the office configuration $\mathrm{C}$, probably because of the greater proportion of ceiling surface.

The insertion of internal dividing panels further slightly improves room acoustic quality in all configurations.

The STI parameter was obtained in the short distance considering the position of two sitting opposite workers who carry out activities with a common interaction of information, by introducing as background noise the one measured during a typical working morning in the case study office (Figure $7, \mathrm{~L}_{\mathrm{Aeq}}=57 \mathrm{~dB}(\mathrm{~A})$ ). . This background noise includes the sound produced by any worker and device present in the office and also the sound coming from the outdoor environment through the façade.

In the case study analyzed in this paper, the façade sound insulation was rather low (in the order of $\mathrm{D}_{2 \mathrm{~m}, \mathrm{nT}, \mathrm{w}}=30 \mathrm{~dB}$ ) and the outdoor environment was quite silent (internal court of the office). It can be considered that the noise coming from outdoors, when considered as a equivalent sound level, as required in the evaluation of the STI, is usually lower than the noise produced inside the office and also in the cases of noisy outdoor environments, as shown in previous studies of the author [42]. The effect of short duration noise events coming from outdoors (such as sirens, passing of very noise vehicles and others) could reduce the intelligibility inside the office when the sound insulation given by the façade is low [18]. Anyway, these short duration noise events are not properly evaluated in the analysis of the Speech Transmission Index, since the study of this parameter requires the use of a continuous and uniform background noise. For this reason, this effect has not been considered in the present study.

In all situations analyzed, the intelligibility improves about 0.2 points from configuration 1 to 3 . Considering that intelligibility is classified as excellent with STI $>0.75$ (Table 3 ) the results are excellent since they are all higher than 0.9 .

In order to evaluate the disturbance produced by the irrelevant speeches for the worker, we also analyzed the STI decay in terms of distance through the $r_{D}$ parameter. The value of $r_{D}$ is very high in configuration 1 for all typologies (Table 6), but especially in offices type $\mathrm{D}$ and $\mathrm{E}$, probably due to the very high volume in office $D$ and the irregularity in office $E$. Class $A\left(r_{D}<5 m\right)$ is not reached under any configuration, even if the offices type $A$ and $C$ are classified in class $B\left(r_{D}<8 \mathrm{~m}\right)$. 
Through an accurate analysis of the results, shown in Figure 11, it can be seen that office A in configuration 4 , already at $3 \mathrm{~m}$ of distance from the source, has a value of STI about 0.55 and is therefore classifiable as a point with poor intelligibility.

Table 6 summarizes all results obtained.
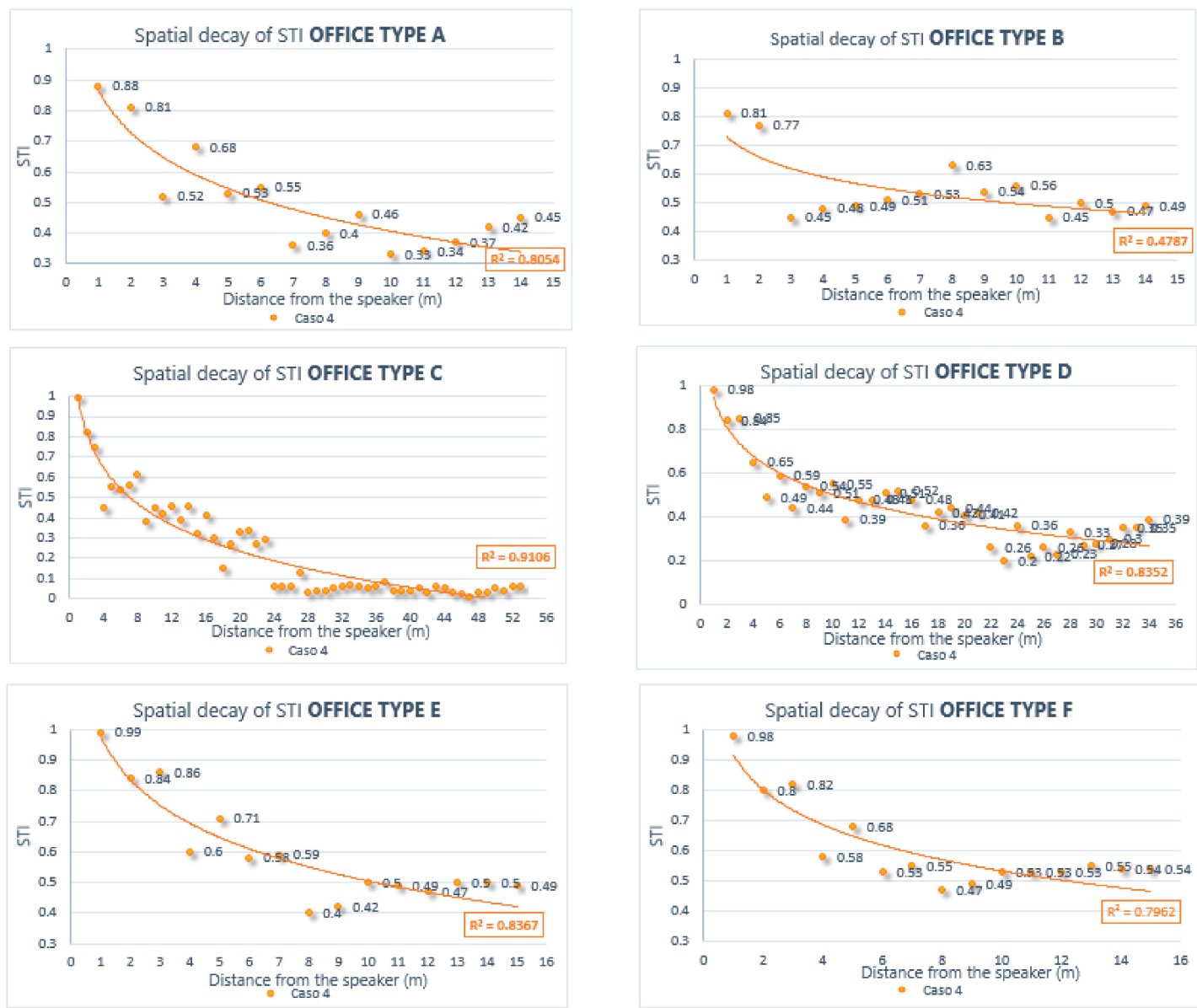

Figure 11. Analysis of spatial decay of STI in all types of offices analyzed, referred to as configuration 4.

Table 6. Summary table of results obtained from the simulations of 24 types offices; the value of STI is referred to the worker placed in front of the speaker (opposite working position); the asterisk $\left({ }^{*}\right)$ means that the dimension found for the distraction distance is greater than the maximum length of the room.

\begin{tabular}{|c|c|c|c|c|c|c|c|c|c|c|c|c|}
\hline & \multicolumn{4}{|c|}{ Office A } & \multicolumn{4}{|c|}{ Office B } & \multicolumn{4}{|c|}{ Office C } \\
\hline & Case 1 & Case 2 & Case 3 & Case 4 & Case 1 & Case 2 & Case 3 & Case 4 & Case 1 & Case 2 & Case 3 & Case 4 \\
\hline $\mathrm{D}_{2, \mathrm{~S}(4-8 \mathrm{~m})}[\mathrm{dB}]$ & 1.4 & 3.1 & 5.0 & 4.6 & 1.1 & 1.9 & 2.6 & 1.9 & 0.7 & 1.5 & 2.2 & 2.3 \\
\hline $\mathrm{D}_{2, \mathrm{~S} \text { (box) }}[\mathrm{dB}]$ & 0.8 & 1.9 & 0.3 & 3.4 & 0 & -0.3 & -0.8 & 0.4 & 0.7 & 1.4 & -1.3 & 0.2 \\
\hline $\mathrm{L}_{\mathrm{p}, \mathrm{A}, \mathrm{S}, 2 \mathrm{~m}}[\mathrm{dBA}]$ & 59.2 & 56.5 & 57.1 & 52.5 & 58.5 & 56.9 & 57.2 & 51.8 & 58.7 & 57.2 & 57.4 & 52.8 \\
\hline $\mathrm{L}_{\mathrm{p}, \mathrm{A}, \mathrm{S}, 4 \mathrm{~m}}[\mathrm{dBA}]$ & 57.5 & 52.2 & 48.4 & 47.8 & 54.7 & 48.5 & 43.9 & 41.4 & 55.3 & 51.7 & 40.8 & 40.3 \\
\hline RT [s] & 2.82 & 0.96 & 0.82 & 0.80 & 3.97 & 1.34 & 1.21 & 1.19 & 3.95 & 1.24 & 0.39 & 0.24 \\
\hline STI & 0.75 & 0.92 & 0.97 & 0.85 & 0.69 & 0.88 & 0.94 & 0.72 & 0.78 & 0.93 & 0.95 & 0.84 \\
\hline $\mathrm{rD}[\mathrm{m}]$ & 18.6 & 19.4 & 9.0 & 6.3 & 12.6 & $21.0^{*}$ & 12.4 & 9.5 & 23.0 & 17.5 & 8.5 & 7.0 \\
\hline
\end{tabular}


Table 6. Cont.

\begin{tabular}{|c|c|c|c|c|c|c|c|c|c|c|c|c|}
\hline & \multicolumn{4}{|c|}{ Office D } & \multicolumn{4}{|c|}{ Office $E$} & \multicolumn{4}{|c|}{ Office $F$} \\
\hline & Case 1 & Case 2 & Case 3 & Case 4 & Case 1 & Case 2 & Case 3 & Case 4 & Case 1 & Case 2 & Case 3 & Case 4 \\
\hline $\mathrm{D}_{2, \mathrm{~S}(4-8 \mathrm{~m})}[\mathrm{dB}]$ & 0.7 & 1.5 & 2.0 & 2.0 & 1.5 & 3.3 & 4.9 & 4.8 & 1.6 & 3.0 & 3.7 & 3.6 \\
\hline $\mathrm{D}_{2, S \text { (box) }}[\mathrm{dB}]$ & 1.0 & 2.0 & -0.2 & 2.2 & 1.3 & 4.2 & -1.3 & 1.8 & 1.4 & 4.0 & -1.0 & 2.1 \\
\hline $\mathrm{L}_{\mathrm{p}, \mathrm{A}, \mathrm{S}, 2 \mathrm{~m}}[\mathrm{dBA}]$ & 59.1 & 57.4 & 57.4 & 55.1 & 59.8 & 56.9 & 56.9 & 52.7 & 58.9 & 56.7 & 56.8 & 52.4 \\
\hline $\mathrm{L}_{\mathrm{p}, \mathrm{A}, \mathrm{S}, \mathrm{m}}[\mathrm{dBA}]$ & 57.3 & 54 & 49.2 & 48.5 & 58.1 & 53.9 & 43.5 & 43.9 & 57.3 & 53.9 & 44.4 & 44.7 \\
\hline RT [s] & 4.11 & 1.32 & 1.11 & 0.94 & 2.76 & 0.87 & 0.71 & 0.64 & 4.48 & 1.4 & 1.17 & 1.03 \\
\hline STI & 0.68 & 0.85 & 0.93 & 0.85 & 0.69 & 0.89 & 0.95 & 0.88 & 0.65 & 0.85 & 0.93 & 0.85 \\
\hline $\mathrm{rD}[\mathrm{m}]$ & 38.0 & 28.0 & 18.0 & 10.0 & $38.5 *$ & 26.7 * & 8.8 & 10.2 & 11.0 & $16.2 *$ & 11.0 & 10.5 \\
\hline
\end{tabular}

\section{Conclusions}

The acoustic improvement in open plan offices can be usually achieved by introducing a sound absorbing false ceiling and high dividing panels, but literature shows that there can be different results depending on the spatial configuration of the office [41].

The variation of the main parameters describing the acoustic quality of a working area have been analyzed with reference to six spatial typologies, which are representative of the most spread kinds of open plan offices. The analysis has been performed by means of a ray tracing software previously validated in a case study of an open plan office.

The best results are obtained with office type A, characterized by a contained volume in height and by equal plan dimensions. Even similar environments with modest plant irregularities show a good response to the treatment.

The introduction of a sound-absorbing ceiling and of separating panels between different working areas is very efficient in all office typologies. Indeed, all of them are in class D with reference to the acoustic classification of open plan offices given by EN ISO 3382-3 in configuration 1 (without absorbing ceiling and partitions), while reach class A or B with the acoustics treatments of configurations 3 and 4 . The described acoustic improvements of offices are significantly positive for the acoustic quality of the spaces in terms of SPL reduction at greater distances.

The Reverberation Time is reduced with the introduction of a sound-absorbing false ceiling in all the spatial typologies, but the variation is more evident in office configuration $C$, characterized by a dimension much greater than the others and reduced height.

The intelligibility between two opposite worker's sittings who carry out activities with a common interaction of information is significantly improved of about 0.2 points from configuration 1 to 3 in almost all office configurations. In all cases, the intelligibility can be classified as excellent with reference to limit values given by the standard IEC 60268-16:2011.

In open plan offices, as shown in scientific literature, the main disturbance elements for the workers are the presence of the irrelevant speech and lack of privacy. With reference to the disturbance produced by the irrelevant speeches for the worker, Class A of EN ISO 3382-3 $\left(r_{D}<5 \mathrm{~m}\right)$ is not reached under any configuration, even if the offices types $A$ and $C$ (with square and rectangular shape but low height) are classified in class $B\left(r_{D}<8 \mathrm{~m}\right)$. Therefore, the irrelevant speech can be considered as a very hard problem that cannot be completely reduced with the introduction of partition panels and sound absorbing ceiling, but also requires other strategies such as the use of sound masking.

The introduction of high partitions between working areas where workers do not need to interact with each other can improve the privacy. However, only good design planning or the refurbishment of the open plan office that creates several spaces based on different activities (working area, team space, coffee area, telephone area, etc.) can improve the privacy of the workers. 
The introduction of the small screens in the table between two opposite working positions (Figure 6, case 4) is almost always irrelevant, as shown to be the differences between the configurations 3 and 4 (Table 6).

Therefore, the essential interventions consist in introducing a sound-absorbing false ceiling and placing partitions at least $1.8 \mathrm{~m}$ high between the work areas that do not have to interact with each other.

On the contrary, it is more difficult and onerous to obtain suitable environmental qualities in spaces with great heights and not well-proportioned dimension in plan.

The only effective solution consists in increasing the sound-absorbing surface and in dividing the work place into specific areas, according to the activities, with the use of high panels.

These results can be used as guidelines for the layout design of open plan offices and for the selection of appropriate materials.

Author Contributions: Conceptualization, S.S.; Data curation, S.D.M.; Methodology, S.S.; Writing—original draft, S.D.M.; Writing - review \& editing, S.D.M., S.S. and G.C.

Funding: This research received no external funding.

Acknowledgments: The authors wish to thank the Regional Agency for the Environmental Protection of Tuscany for making available the office of the case study.

Conflicts of Interest: The authors declare no conflict of interest.

\section{References}

1. Navai, M.; Veitch, J.A. Acoustic Satisfaction in Open-Plan Offices: Review and Recommendations; IRC-RR-151; National Research Council of Canada, Institute for Research in Construction: Ottawa, ON, Canada, 2003; Available online: https:/ / nparc.nrc-cnrc.gc.ca/eng/view/fulltext/?id=dfaa533c-57c3-4f06-9be7-5d393d4c163b (accessed on 13 September 2018).

2. Keighley, E.C. The determination of acceptability criteria for office noise. J. Sound Vib. 1966, 4, 73-87. Available online: https:/ / www.sciencedirect.com/science/article/pii/0022460\$ times $\$ 66901556$ (accessed on 16 September 2018). [CrossRef]

3. Kim, J.; De Dear, R. Workspace satisfaction: The privacy-communication trade-off in open-plan offices. J. Environ. Psychol. 2013, 36, 18-26. [CrossRef]

4. Schlittmeier, S.J.; Liebl, A. The effects of intelligible irrelevant background speech in offices-Cognitive disturbance, annoyance, and solutions. Facilities 2015, 33, 61-75. [CrossRef]

5. Hongisto, V.; Haapakangas, A.; Hyönä, J.; Kokko, J.; Keränen, J. Effects of unattended speech on performance and subjective distraction: The role of acoustic design in open-plan offices. Appl. Acoust. 2014, 86, 1-16. [CrossRef]

6. Varjo, J.; Hongisto, V.; Haapakangas, A.; Maula, H.; Koskela, H.; Hyönä, J. Simultaneous effects of irrelevant speech, temperature and ventilation rate on performance and satisfaction in open-plan office. J. Environ. Psychol. 2015, 44, 16-33. [CrossRef]

7. Sylke, N. Ergonomics workplace design. In Work Environments, 2nd ed.; Schittich, C., Ed.; Birkhauser: Basel, Switzerland, 2013; Volume 56, pp. 39-43.

8. Machner, R. Acoustic design in open-plan offices, In Work Environments, 2nd ed.; Schittich, C., Ed.; Birkhauser: Basel, Switzerland, 2013; Volume 56, pp. 45-49.

9. Boubekri, M.; Haghighat, F. Windows and environmental satisfaction: A survey study of an office building. Indoor Environ. 1993, 3, 164-172. [CrossRef]

10. Freihoefer, K.; Guerin, D.; Martin, C.; Kim, H.Y.; Brigham, J.K. Occupants' satisfaction with, and physical readings of, thermal, acoustic, and lighting conditions of sustainable office workspaces. Indoor Built Environ. 2015, 24, 457-472. [CrossRef]

11. Vellenga, S.; Bouwhuis, T.; Höngens, T. Proposed method for measuring 'liveliness' in open plan offices. In Proceedings of the 24th International Congress on Sound and Vibration, London, UK, 23-27 July 2017.

12. Morawska, L. Droplet fate in indoor environments, or can we prevent the spread of infection? Indoor Air 2006, 16, 335-347. [CrossRef] [PubMed]

13. Bouilly, J.; Limam, K.; Béghein, C.; Allard, F. Effect of ventilation strategies on particle decay rates indoors: An experimental and modelling study. Atmos. Environ. 2005, 39, 4885-4892. [CrossRef] 
14. Zhao, B.; Wu, J. Particle deposition in indoor environments: Analysis of influencing factors. J. Hazard. Mater. 2007, 147, 439-448. [CrossRef] [PubMed]

15. Park, D.; Chang, S. Numerical investigation of thermal comfort and transport of expiratory contaminants in a ventilated office with an air curtain system. Indoor Built Environ. 2018, 1-21. [CrossRef]

16. EN 15251:2007. Indoor Environmental Input Parameters for Design and Assessment of Energy Performance of Buildings Addressing Indoor Air Quality, Thermal Environment, Lighting and Acoustics; International Organization for Standardization: Geneva, Switzerland, May 2007.

17. Casini, D.; Cellai, G.; Fogola, J.; Scamoni, F.; Secchi, S. Correlation between facade sound insulation and urban noise: A contribution to the acoustic classification of existing buildings. Build. Acoust. 2016, 23, 145-158. [CrossRef]

18. Secchi, S.; Brambilla, G.; Casini, D.; Cellai, G. A Method to Estimate Students' Exposure to Road Traffic Noise Events. Environments 2018, 5, 39. [CrossRef]

19. Furnari, M. Manuale di Progettazione Uffici; Mancosu Editore: Roma, Italy, 2013; Volume D32-D55, p. 8896589126. (In Italian)

20. Nocke, C. Open Plan Offices-classification scheme based on ISO 3382-3 Parameters. In Proceedings of the Internoise, Melbourne, Australia, 16-19 November 2014.

21. ISO 3382-3:2012. Acoustics-Measurement of Room Acoustic Parameters-Part 3: Open Plan Offices; International Organization for Standardization: Geneva, Switzerland, January 2012.

22. ISO 14257:2001. Measurement and Parametric Description of Spatial Sound Distribution Curves in Workrooms for Evaluation of Their Acoustical Performance; International Organization for Standardization: Geneva, Switzerland, October 2001.

23. ISO/DIS 19488:2018. Acoustics-Acoustic Classification of Dwellings; International Organization for Standardization: Geneva, Switzerland, October 2018.

24. Hongisto, V.; Haapakangas, A.; Varyjo, J.; Helenius, R.; Koskela, H. Refurbishment of an open-plan office-Environmental and job satisfaction. J. Environ. Psychol. 2016, 45, 176-191. [CrossRef]

25. Virjonen, P.; Keränen, J.; Hongisto, V. Determination of acoustical conditions in open-plan offices-Proposal for new measurement method and target values. Acta Acust. United Acust. 2009, 95, 279-290. [CrossRef]

26. Nilsson, E.; Hellstom, B. Room acoustic design in open plan offices. In Proceedings of the 10eme Cogres Francais d'Acoustique, Lyon, France, 12-16 April 2010.

27. Keranen, J.; Virjonen, P.; Hongisto, V. A new model for acoustic of open plan offices. In Proceedings of the ICA, Madrid, Spain, 2-7 September 2007.

28. Kohlert, C. Wellbeing at new ways of working-acoustics. In Proceedings of the Internoise, Hamburg, Germany, 21-24 August 2016.

29. Keränen, J.; Hongisto, V.; Hakala, J.; Elorza, D.O. Speech privacy in an open plan office with different room acoustic conditions. In Proceedings of the Forum Acusticum, Aalborg, Denmark, 27 June-1 July 2011.

30. Kostallari, K.; Parizet, E.; Chevret, P.; Amato, J.; Galy, E. Irrelevant speech effect in open plan offices: A laboratory study. In Proceedings of the 24th International Congress on Sound and Vibration, London, UK, 23-27 July 2017.

31. Romano, R.; Quindici, R.; Dragonetti, R. Approccio metodologico per la valutazione del disturbo da rumore in ambienti di lavoro open-space in cui si svolgono attività che richiedono concentrazione. In Proceedings of the II Conference of Forensic Engeneering, Pisa, Italy, 15-17 November 2012. (In Italian)

32. Sarwono, J.; Larasati, A.E.; Novianto, W.N.I.; Sihara, I.; Utami, S.S. Simulation of several open plan office design to improve speech privacy condition without additional acoustic treatment. Procedia Soc. Behav. Sci. 2015, 184, 315-321. [CrossRef]

33. Haapakangas, A.; Hongisto, V.; Varjo, J.; Lahtinen, M. Benefits of quiet workspaces in open-plan offices e evidence from two office relocations. J. Environ. Psychol. 2018, 56, 63-75. [CrossRef]

34. Secchi, S.; Asdrubali, F.; Cellai, G.; Nannipieri, E.; Rotili, A.; Vannucchi, I. Experimental and environmental analysis of new sound-absorbing and insulating elements in recycled cardboard. J. Build. Eng. 2016, 5, 1-12. [CrossRef]

35. Hongisto, V. Effects of sound masking on workers-A case study in a land-escaped office. In Proceedings of the 9th ICBEN, Foxwoods, Mashantucket, 21-25 July 2008.

36. Farina, A. Pyramid tracing vs. ray tracing for the simulation of sound propagation in large rooms. In Transactions on the Built Environment; WIT Press: Southampton, UK, 1995; Volume 10, ISSN 1743-3509. 
37. Farina, A. RAMSETE-A new Pyramid Tracer for medium and large scale acoustic problems. In Proceedings of the EURO-NOISE 95 Conference, Lyon, France, 21-23 March 1995.

38. Scrosati, C.; Scamoni, F.; Prato, A.; Secchi, S.; Fausti, P.; Astolfi, A.; Barbaresi, L.; D’Alessandro, F.; Di Bella, A.; Schenone, C.; et al. Uncertainty of Facade Sound Insulation by a Round Robin Test. Evaluations of Low-Frequency Procedure and Single Numbers. Build. Environ. 2016, 105, 253-266. [CrossRef]

39. ISO 9921:2003. Ergonomics-Assessment of Speech Communication; International Organization for Standardization: Geneva, Switzerland, October 2003.

40. Delle Macchie, S. The Acoustic Issues in Open Plan Office. Master's Thesis, School of Architecture, Florence, Italy, 14 February 2017.

41. Keränen, J.; Hongisto, V. Prediction of the spatial decay of speech in open-plan Offices. Appl. Acoust. 2013, 74, 1315-1325. [CrossRef]

42. Secchi, S.; Astolfi, A.; Calosso, G.; Casini, D.; Cellai, G.; Scamoni, F.; Scrosati, C.; Shtrepi, L. Effect of outdoor noise and façade sound insulation on indoor acoustic environment of Italian schools. Appl. Acoust. 2017, 126, 120-130. [CrossRef]

(C) 2018 by the authors. Licensee MDPI, Basel, Switzerland. This article is an open access article distributed under the terms and conditions of the Creative Commons Attribution (CC BY) license (http:/ / creativecommons.org/licenses/by/4.0/). 